\title{
Netnography and Design Thinking: \\ Development and Illustration in the Vegan Food Industry
}

\section{Abstract \\ Purpose}

To strengthen the process of design thinking by aligning it with netnography, specifically auto-netnography, which we assert is particularly suited to the task of studying and enriching the actions of 'designerly types' who seek to fashion monetizable businesses.

\section{Design/methodology/approach}

We conduct an auto-netnography with a structure divined from established design thinking theory - that of empathizing, defining, ideating, prototyping and testing - to afford an understanding of how a popular health food influencer designs a successful vegan restaurant.

\section{Findings}

We illustrate the empathetic relationship between a long-term audience member and an entrepreneur/designer/marketer. Our intimate cultural analysis reveals the nature of their symbiotic entwinement. In a way that few other methods could, our method shows how this sense of reciprocity, deepens over time.

\section{Research limitations/implications}

Conducting an auto-netnography is a prolonged and difficult task. Nonetheless, by revealing the rituals, expectations, roles and routines of content creators, designers and followers, we illustrate exciting possibilities for the enactment and development of design thinking in the marketing field.

\section{Practical implications}

Designerly types like marketers and content creators should closely study, listen to and interact with consumers by employing a similarly staged process that draws equally from design thinking and autonetnography.

\section{Originality}

Prior to this study, existing research has not previously linked design thinking with either netnographic or autonetnographic research.

\section{Keywords:}

Content Creators, Influencers, Wellbeing, Food, Auto-Netnography, Design Thinking 


\section{Netnography and Design Thinking: Development and Illustration in the Vegan Food Industry}

\section{Introduction}

About three decades ago, Smith and Reinertsen (1991) introduced design thinking into the academic literature. Lockwood (2009) declared that attention to the application of design thinking was the key to integrating innovation, customer experience, and brand value, while Neumeier $(2009$, p. 7) went further arguing that it was "the management innovation destined to kick Six Sigma off its throne". Addressing his comments to managers, he declared that it would "take over your marketing department, move into your research and development labs, transform your processes, and ignite your culture." Since then, interest in the field of design thinking has continued to grow. Many view its extreme flexibility and responsiveness, coupled with its ability to solve intractable problems, as a means of salvation in an increasingly perilous and uncertain world (Liedtka, 2015; Dell'Era et al., 2020).

Although the discipline of design thinking has been developed by scholars and practitioners in marketing, service, urban planning and a host of other fields (Kurokawa, 2015; Pressman, 2018; Christensen et al., 2017), it is fair to say that many believe its potential has not been fully realized. In a critical review, Iskander (2018, p. np) argues that "design thinking is poorly defined; that the case for its use relies more on anecdotes than data; that it is little more than basic common sense, repackaged and then marketed for a hefty consulting fee." While some of these charges are overwrought, design thinking's possibilities have been under-recognized partly because it seems unclear, and has only been loosely linked to other managerial and marketing methods and approaches. In this paper, we propose and demonstrate linking design thinking with netnography.

Design thinking has recently drawn on disciplines such as anthropology and sociology (Reyero, 2019; Gregory, 2018). Reyero (2019, np), considers that the ability of anthropologists "to visibilize the invisible, ask pertinent questions, and define social problems" is a "perfect match" to the designer needs that "are dedicated to developing solutions to problems". Liedtka (2014) asserts and demonstrates the utility of ethnographic techniques as a design tool. Design thinking and ethnography both attempt to see things from the point of view of the consumer and acquire meaningful cultural insights. The anthropological technique of ethnography has been widely applied in the field of marketing. According to Mariampolski (2006, p. 7), applied ethnography is "understood as a methodological orientation that emphasizes direct contact and observation of the consumer in the natural context of product acquisition and usage". "Netnography" is an extension of ethnography that applies it and other related qualitative research practices to "the cultural experiences that encompass and are reflected within the terraces, networks, and systems of social media" (Kozinets 2020, p. 19). Although combinations of design and netnography are still rare, netnography has been used to explore human-product interactions and to inform designs of online services such as games and classes (Wang, 2018, O'Reilly et al., 2007).

We believe that building bridges between related methods and design thinking can strengthen both approaches and open up a vital cross-disciplinary discourse. Our goal in this paper is thus to further strengthen the process of design thinking by exploring and demonstrating its conceptual and practical alignments with ethnography, netnography, and a newer variant of netnography called auto-netnography. Given that we understand design, as Friedman and Stolterman (2015, p. x) explain, "as thought and action for solving problems and imagining new futures", our article is designed to appeal not just to those who design products, but to all 
designerly types. This might include marketers, content creators and influencers who create experiences and new businesses, but more broadly it might also appeal to anyone seeking to offer any kind of value to others in the world. We begin by describing the theoretical edifice upon which we will structure our findings. We then elaborate on our methodological approach. Finally, we conduct an auto-netnography through the lens of design thinking in line with the accepted Stanford Design School processes that best characterise it - empathise, define, ideate, prototype and test. We conclude with some thoughts on the ramifications of our study.

\section{Design Thinking, Netnography, and Auto-netnography}

In this section, we explore the linkage between design thinking, netnography, and autonetnography as a prelude to demonstrating their synthesis in an empirical study situated in the food industry. The genealogy of the term 'design' is historically rich, discursively malleable and intimately related to the origins of design thinking. Originally pertaining to the visual arts, $19^{\text {th }}$ century artist Michelangelo used the word 'disegno' as pertaining to both the ability to draw and the intellectual capacity to formulate a design (Krupinska, 2014). Design has since iteratively evolved as representing the visual styling of products (Rundle, 2013), the creation and planning of a products function (Rathbone, 1950) and as a perspective in itself (Saariluoma et al, 2016). A key period of intensively re-defining the meaning of design occurred in the mid-late $20^{\text {th }}$ century. At this time, incremental advances by theorists such as Herbert Simon (Simon, 1968), Horst Rittel and Melvin Webber (Rittel and Webber, 1973), slowly led to Peter Rowe (1987) developing the term 'design thinking' as a flexible, problemsolving technique. It became associated not necessarily relating with making things, but as a holistic, experimental, and human-centred enterprise. Interestingly, Rowe (1987) used ethnography to understand designers. We also follow this tradition of conducting in-depth qualitative fieldwork to uncover innovative design thinking processes.

Despite the fact that research and design thinking share similarities, historical tensions have found them at odds with each other (Archer, 1995). Design thinking tends to be more concerned with creating a possible future; design focuses on 'how to' whereas research has been preoccupied with 'what is' (Stappers et al., 2015). Increasingly, however, ethnography has been recognised for its ability to reveal hidden possibilities, such as product benefits that marketers were previously unaware of (Mariampolski 2006, p. 204). Applied netnography has been used in a vast range of industrial applications to gain consumer insights and design a range of successful products. For example, one of the most innovative design firms in Germany, a Munich-based company called HYVE, regularly uses netnography in order to design next generation products. In one of their success stories, which has also been written up as a Harvard Business School Case, they worked with Beiersdorf/Nivea to research and design a new Nivea deodorant (Bilgram, Bartl, and Biel, 2011). The company used netnography to go online and monitor a range of conversations regarding deodorant. After noting that many online consumers were linking their deodorant to sweat stains and laundryrelated concerns, the company worked with designers and chemical engineers to develop a new sub-brand Nivea 'Invisible for Black and White' no-stain deodorant. The product became the single most successful product launch in the history of the brand.

HYVE utilizes a 6-step process for netnography. It moves from research definition and online community selection, to qualitative data analysis, insight generation, consumer insights development and product services and solutions. As we can see, the definition stage of 
netnography is closely related to the define stage of the popular Stanford D-school five stage process, which was based on Herbert Simon's seminal text "The Sciences of the Artificial" (Simon, 1968). The empathise element of the design process is developed in relation to netnography through social media selection processes and online data collection and analysis. Ideation relates to insight generation and especially to consumer insight development in netnography. And finally, there is overlap between the final stage of HYVE's netnography process, product services and solutions, and the prototype and testing phases of the D-school process.

In this study, we extend netnography into auto-netnography, defined as "an approach to netnography that highlights the role of the netnographer's experiences of his or her own online experiences" (Kozinets and Kedzior, 2009, p. 8). The "auto" in netnography thus stands for "autobiographical", as the researcher is encouraged to engage deeply in social media and related activities regarding the research topic, to carefully capture and document them "through the careful personal observation of online participation" and paying attention to the interrelationship of various experiences, both offline and online, and to use these as grist for the mill of practical and/or theory development efforts (Kozinets and Kedzior 2009, p. 8). Auto-netnography has become established via the work by a number of marketing researchers (see: Wilkinson and Patterson, 2014; Villegas, 2018; Syrjäläyrjä and Norrgrann, 2018), and Howard, 2020). In the section that follows, we further develop the linkages between netnography and design thinking, and emphasise some of the elements highlighted by the use of auto-netnography.

\section{Design Thinking Processes}

There are many competing normative conceptualisations of design thinking. Remarkably, in their extensive review of the literature, Micheli at al. (2019) identify eight different tools that designerly types can utilise. A popular approach that has garnered considerable traction is the 'three Gears of Design' model outlined by Heather Fraser from the Rotman School of Management (Carlgren et al. 2016). Nonetheless, as we have previously noted, the model which has undoubtedly garnered the most attention is Stanford D-school's five-stage offering, thus for the purposes of this study, we will cleave closely to it. It has clear parallels with auto-netnography, which we elaborate on below.

\section{Empathise}

According to design thinking theory, an innovator's principal prerogative should be to empathise with one's colleagues, end users, customers or audience (Köppen and Meinel 2015). Demonstrating empathy is best achieved by putting oneself in another's shoes in order to feel and share their emotions, experiences and intentions (Kolko, 2014). An appreciation for human connectedness and empathy also resides at the heart of netnography. Viewing it not only as a methodological matter, but one of ethics, Kozinets $(2020$, p. 186) is clear about the link between netnography and empathy: "We should seek empathy in the conduct of our research, empathy in our interpretations, and empathy in the presentation of our research results. Empathy is ultimately what powers a good netnography”. While for designerly types, the human-centric nature of an empathetic understanding helps them to humanize their technological innovations (Macdonald, 2003). Similarly, empathy is what allows netnographers to understand the human realities behind the flurry of images, video, and text flowing across the surface of social media. The advantage of auto-netnography is that it acutely attunes researchers to their own intuitions and impressions. It is this sense of selfawareness of the researcher and cultural participant that fundamentally links netnography, auto-netnography, and design thinking. 


\section{Define}

Dwelling for a time in the 'problemspace' is the second stage of design thinking. Developing an understanding of its constraints can help in reaching precise solutions. During the 'definition' stage, designerly types think deeply about the needs of their intended audience. Practicalities such as project timelines, where it will be used, budget and the overarching rationale for the project are also established at this stage (Best, 2006). Defining encourages the creation of a project brief which specifies the particularities of the task. In applications, netnography has exactly the same focus, but applies these elements to the research process whose outcome, as the examples above show, may well be a product such as a new deodorant. Research questions in a netnography or auto-netnography are determined by the motivations of inquiry, extant literature and understanding the nature of diverse aspects of a phenomenon (Rodgers and Yee, 2015). Moreover, sketching the boundaries of a netnographic research project also requires attention to practical questions such as how long the project will be, which data to collect, where to store data and ethical considerations (Kozinets, 2015), often resulting in the creation of a research proposal. Again, the two processes parallel one another: the design process and netnography both organise and focus their objective through problem definition.

\section{Ideate}

The third stage of the design thinking process is ideation, or 'thinking in alternatives' (Brenner and Uebernickel, 2016). In this mode, design thinking becomes more spontaneous and iterative. Artistic skills are employed, such as sketching or CAD (Jonson, 2005). Designers produce and communicate possible solutions to the project brief, whereby an 'idea' can be understood as something visual, concrete or abstract (Jonson, 2005). During this time, the designer is still very much in the 'fuzzy front end' of their project. Ideation is also incredibly valuable in any research process, but particularly when undertaking in-depth qualitative methods such as netnography. Like a designer, a netnographer always begins with an idea, sometimes purely inductive, curiosity driven, or alternatively as a direct response to the needs of humanity. Netnographic researchers also have to ideate, as they seek, search and find the appropriate community where they can set up their investigative endeavours (Kozinets, 2020). Kozinets $(2015,2020)$ encourages netnographers to think like designers, using techniques such as "artifying" and "visual abstraction" which encourage drawing, collage, visualization, and other artistic representation as a key part of the data interpretation process. There are also elements of ideation when searching for 'light bulb' moments in the deep trenches of abductive data analysis, argument construction, or the iterative re-drafting of research findings (Patterson and Ashman, 2021). Auto-netnography similarly encourages the researcher to go deep, to build on their own creativity, talent, and impressions in their quest to produce a penetrating cultural understanding. Thus, design thinking and netnography both encourage an ideation process focused on open-endedness, creativity, and the pursuit of the novel.

\section{Prototype}

Many treatments of design thinking stress that producing tangible prototypes is an essential way of establishing the viability of products among potential user communities (Polaine, Løvlie and Reason, 2013). Prototyping acts as the soft launch of a product, a way to 'fail early to succeed sooner' (Hillgren et al., 2011). The prototyping phase helps designers see the reality of a product in a consumer's hands and assists them in creating iterative loops which accelerates deep learning and discovery (Pressman, 2018). As explained above, design oriented netnographers in industry often work with professional industrial designers to 
prototype the outcome of their research process. At HYVE, the usual outcome of a netnography research project is the collaboration with a design team and the construction of several product prototypes that better serve the needs of customers based on the research findings. Netnography assists designers gain natural feedback by unobtrusively alighting upon conversations about the upsides and downsides of their products. Being ensconced in the milieu of a netnographic study, as with an auto-netnography, means that the researcher is present when changes occur, such as when new products are introduced into a specific marketplace. This allows an auto-netnographer to reflect upon their own and other's experiences of the new product or prototype in a naturalistic real-time and real-world setting.

\section{Test}

The final stage in design thinking is to test. Testing is the measurement of a product's success. During testing the designer "evaluates whether their experiments in innovation yield productive results, judged by both the individual and society as a whole" (Buchanan, 1992, p.11). This stage is most alien to the research process of netnography, which, as a research process, relinquishes the final handoff of any design elements to designerly types. Netnography's academic practitioners test their ideas through the publishing of research, and hear sentiments echoed back via citations and feedback from research colleagues. However, testing products is much more rooted in the everyday experience of designers and their working teams, and as such depends on the successful provocation of market behaviour through empathetic design thinking (Kolko, 2014). Nonetheless, netnography and autonetnography together play vital roles in allowing designerly types to create stuff, be it a product or experience that contains a deep and grounded understanding of consumers.

In summary, the above sections illustrate the many conjunctions and overlaps of netnography, auto-netnography, and design. In the following section, we illustrate how these work in practice with a study of an online food influencer who leveraged her social media fan following to design a novel vegan food brand and its accompanying physical and online experiences.

\section{Contextual Background}

Social media today has been a game-changer for business and marketing. It has altered public discourse, transformed the way people shop, helped empower a new age of protest, and has been a crucial lifeline in the isolated age of COVID-19. What is more, many food-oriented YouTube influencers have found fame and fortune in the digital gold rush of social media exposure (Ashman et al, 2018; Mardon et al, 2018). Their transformation from experimental grassroot amateurs into sponsored, skilled professionals capable of creating desirous products and services has been noted as especially worthy of study, particularly related to the realms of food production and consumption (Coates et al 2019, Kozinets et al, 2017, Patterson, Kozinets, and Ashman 2019). In the food industry, numerous foodies and small restauranteurs have leveraged their video content to earn advertising revenue, launch cookbooks, and promote popup eateries and new restaurants. In keeping with the everchanging vagaries of fashion and taste, and the vanity of small differences that distinguishes each of them, self-proclaimed foodies frequent interesting restaurants and, while at home, prepare what they typically describe as 'life-transforming, plant-based super meals.' Through their blogs, selfies, posts, vlogs, and associated content, content creators or 'influencers' are in the serious business of detailing an idealised lifestyle, which they hope their followers both admire and desire (Raun 2018). 
During the process of developing and posting an ongoing stream of relevant content to followers, influencers receive large amounts of feedback akin to conducting their own ongoing market research. Quantitative feedback is available in the form of views, likes, and dislikes, subscribers, trending scores, number of shares, comments and of course the monetary value gained from their content. Qualitative feedback takes the form of comments and discussions attached to each piece of content. These interactions are often plentiful, detailed and interactive. Comments tend to cover all sorts of topics in a naturalistic and personal way and as such, allow the content creator to become intimate with the needs, habits, language, and worldview of their audience, enabling them to meaningfully translate marketing hype into communal language, as Kozinets et al. (2010) explained. Such feedback offers an advantage during the design of content and products because content creators are able to deep dive into their follower's uninhibited mind. If influencers are reflexive enough, they can develop a strong connection and empathy with their community.

Through using this highly interactive, iterative and reflective online environment, content creators are able to produce meaningful, resonant content involving personal reflection and crowd-sourced feedback. This can lead to commercial opportunities. We have observed health food influencers leveraging their social media followings as data for the design for such opportunities, which spans from producing content to creating products typically bought to market by traditionally established businesses (see Table 1). In this paper we demonstrate that the production and maintenance of a social media following is an important facet of modern, innovative and highly empathetic design thinking. To uncover the intimate connection that influencers have with their followers, and to chronicle the production of a product from its social media inception to the marketplace, this paper presents an autonetnographic account of one such health food influencer, Monami Frost. Written by one of her most ardent followers, who also happens to be the lead author of this project, we witness how Monami, through engaging with social media, successfully acquired deep cultural knowledge about her community and, as a consequence, launched a restaurant to cater specifically to her follower's cravings.

\section{Insert Table 1:}

\section{Method}

As part of an on-going research project, this paper draws and builds upon ethnographic research conducted in the online space of food and drink exhibition. As such, our first author lurked for eight years among health food influencers. She continued to engage in various ways with social media health food influencers and, during this time, she conducted the autonetnographic practice of personal introspection and online participation while viewing content on YouTube and Instagram. Auto-netnography enabled her to create detailed insights into the everyday workings of these platforms and to reflect on how she consumed, functioned and interacted with them. Writing about 'auto-ethnography', in his classic work, Hayano (1979 p. 100) writes that this type of ethnographic reflexivity is appropriate when researchers have acquired an "intimate familiarity with certain subcultural, creational, or occupational groups". The history, length, and depth of this extensive ethnographic immersion equipped her with such qualities. The co-authors, while not specifically conducting the auto-netnography themselves, possessed a significant depth of knowledge from our previous ethnographic experiences and provided a theoretical and methodologically robust sounding board. In the following sections, we detail our data collection, analysis procedures, and findings. 


\section{Data Collection and Analysis}

Our auto-netnographic data set is comprised of over six thousand screenshots from Instagram, Facebook and YouTube, a catalogue of 403 YouTube videos, two notebooks of introspective field notes, and the observational records from 9 in-person ethnographic restaurant visits. Our online data collection approach was bimodal. For the data collected on YouTube, we followed the upload schedule of a variety of health and wellness influencers (as seen in Table 1), focusing in on Monami Frost as we refined our project. For the data collected from Facebook and Instagram, our first author dwelled daily on these platforms, adventurously investigating the world of health and wellness, picking up vivid and creative impressions, and ultimately focusing on sites of interest, including the Frost Burgers pages and Monami Frost's personal feeds. Consequently, our data set comprises a large corpus of visual online 'traces' comprising textual, graphic, photographic and audiovisual media (Kozinets, 2020). For this method, screenshots were useful in preserving the full visual context of the social media experience. To bring meaning, order and structure to this multimedia dataset, we performed a hermeneutic, visual and "inter-penetration" data analysis involving all authors (Kozinets 2015). During this process, we moved abductively between our theoretical framing and our expansive data set (Alvesson and Sköldberg, 2009). While the first author was responsible for the creation of the auto-netnographic narrative and the netnographic data within it, the second and third author were present throughout the process in the form of regular conversations and research assistance.

\section{Conceptual Framework for Study Findings}

Prior to presenting our auto-netnographic account, we introduce a framework to help the reader follow crucial points as the findings of the auto-netnography unfurl. The diagram is specific to the case under investigation. Its five consecutive processual steps illustrate how at every given stage, content creator and follower are linked together via symbiotic feedback loops that grow stronger as the product or service comes more firmly into being. The multiperspectival market design process, so-called due to the melding of the perspectives of both content creator and their legion of followers, commences slowly and iteratively. First, is the empathise stage, which exists in the hazy origins of network formation where the content creator's offering is inchoate and ill-defined. Here the content creator listens intently with a view to finding common ground, perhaps in relation to shared values and interests, with a still nascent, but growing, band of followers Second, is the define stage where the content creator, spurred on by followers who frequently mirror their activities, thereby validating them, becomes increasingly certain about their expert authority, in this case, in relation to the preparation and consumption of vegan fast food. Third, is the ideate stage where the content creator develops a range of monetizable ideas that are both attuned to, and developed in loose conjunction with, their followers who levels of excitement and interaction are indicative of likely success or failure. In this fashion, followers are critical friends rather than nodding yes men who simply green light everything that hails forth from the factory of ideas. Fourth, is where fleshed out experimental prototypes are created and shared for comment and delectation. Fifth, is the test stage where the full retail offering is created and tested with a signed-up follower who is happy to become a customer and advocate of said business venture. These relationships are not always explicitly evidenced, but our research demonstrates their existence through describing the first author's account of such an 
assembled network of social media platforms, content creators, followers', physical products and reflective experiences. Our findings demonstrate that these spaces, experiences, objects and practices implicate the resultant entrepreneurial outcome and shape the design thinking process.

\section{Insert Figure 1:}

Next, we share our auto-netnographic account to provide evidence regarding how health food influencers use design thinking within their carefully curated social media oeuvre and how this relates to their followers' wellbeing. In keeping with auto-netnographic tradition, the account is presented as a first-person narrative.

\section{Study Findings}

Monami Frost is a 26-year-old YouTube star turned entrepreneur, based in Liverpool, England. Monami joined YouTube in 2012, and since then has built a following of $702 \mathrm{k}$ regular subscribers, has 74,555,443 views of her videos, and 1.6 million Instagram followers. During her time on social media, Monami has been adept at monetizing her following in a variety of different ways. For instance, she has authored and sold a successful cookbook entitled "Vegan Home Cooking". She also runs a streetwear brand called "Frost Streetwear" that sells her designs: clothes, signed posters and books, kidswear, activewear and gift boxes. It was the success of these earlier ventures that spurred her on to open a vegan restaurant in Liverpool, UK, called Frost Burgers. Her creation of this restaurant is my main focus. My auto-netnographic findings will move through the way that Monami Frost implicitly follows the D-school's five step process, in her own unique fashion.

\section{Empathising with online consumers}

My prolonged observation of Monami at work in her online spaces reveals an extraordinary capacity to demonstrate empathy, which, in a way, is remarkable given the very distinctive image she projects. Let me explain. She is a densely and artfully tattooed, strongly accented Latvian. Still in her twenties, she lives in North West England, alongside her husband and two children. Endearingly, she is often a little tongue-tied, speaks circuitously and makes strange gestures. Above all, she is charismatic. Her sexy, radiant confidence and admirable aesthetic autonomy ensure that she stands out and gets noticed.

On a personal level, I feel a profound connection with her content. I enjoy dropping into her life for a time. Let her take the reins. Allow her to lead, while I follow. When watching her, I get a sense that I am not alone. That I am okay. Her message of self-acceptance seeps through me. Seeing how she functions, helps me function more productively. She is my role model, and she responds to me, and the rest of her audience, honestly and intimately. I find refuge in her content. When I watch her videos, I don't feel that I am wasting time. In a way, tuning into her content, stimulates my empathetic response. Empathy breeds empathy. This allows me to see myself as part of a world beyond the limits of my own mind and body.

Monami shows empathy most powerfully when she is raw, honest and relatable. She tells her community about the miniscule details of her life, such as her challenges with mental health. Such a high level of disclosure builds intimacy and trust. She gives her followers the inside track, and often they demonstrate appreciation for this by sharing their own trials and tribulations. For example, on a recent YouTube video Monami discusses being in the public 
eye and how she experiences anxiety in her daily life. In this video, Monami describes her ongoing struggle with confidence. The following data is drawn from the video and a related Instagram post.

"People don't understand. They think I am just an online person and they forget that I'm just just like them. That I'm human...people feel that because I have like a lot of followers or something then I am something else and they disconnect that from like a reality" (Monami on Instagram).

"I have just finished watching your video @monamifrost on mental health and I just wanted to say THANK YOU...It's not easy talking about anxiety. There is so much stigma attached to it, but you are so brave to talk about it. I suffer with it greatly and I related to a lot of the feelings you get. You and your husband are such inspirations. Thank you" (Poster on Instagram reacting to video).

"too much stigma and you never know who can suffer from it! Thank you for your kind words! Sending lots of love" (Monami posting a reply on Instagram).

“@monamifrost take care and thank you again xx you are awesome!” (Poster replying on Instagram)

This is just one example among many where Monami strikes a chord with her followers. In this case, her community responded with 78,450 views and 129 overwhelmingly positive comments. Displays of such deep commonality with her followers are demonstrable throughout her content. Through developing her YouTube channel Monami seeks to continually understand her audience stating that she 'loves reading' their comments and describing how her community is 'part of her family' (Monami Frost on YouTube, 2019).

\section{Defining the influencer as a food authority and then food producer}

Monami, of course, didn't begin her journey on YouTube with a crystal-clear remit of what value she could bring to the platform, or of what specific problem her talents could address. In her first tentative YouTube video, she simply articulates that her purpose will be to "show the adventures that me and my family get up to...sharing some great vegan recipes and doing some makeup tutorials" (Monami Frost on YouTube, 2015). She asked her followers to leave questions, queries and ideas in the comments section so that she could garner feedback. Performing this scoping exercise shows the human-centred nature of her channel. Her followers actually led in defining the purview of her interests. Monami might never have officially crafted a project brief but viewing her content over time makes it clear that she intuitively knew that understanding what her audience liked aided in the process of defining her innate value, and ultimately helped her become a successful vegan entrepreneur. For instance, in a recent video about the creation of her restaurant she says: "If you weren't there behind the screen none of this would be remotely possible. I wouldn't be here, where I am now, without you guys..." (Monami Frost, YouTube, 118,165 views).

Eventually, it became clear that her true calling, her raison d'etre was to help people make healthy, plant-based food choices. Monami's most popular videos are, like most lifestyle vloggers, about the food that she eats in a regular day. Viewers obsess about what content creators like her put in their mouths. The format of such videos varies from unadorned, unedited realism where cooking takes an age and every mouth-entering morsel is shown on screen, to being more artfully and sele2ctively shot. Observing someone's day and tracking their meals, according to many YouTube fans, is their favourite activity. In Korea, Mukbang videos that feature the social media host livestreaming while they eat along with their audience, are extremely popular. Monami gleans from the feedback she receives that catering to this voyeuristic and vicarious pleasure is an excellent means of monetizing content and understanding her market, so much so that she asks her followers to tell her what to make: "Suggestions for Vegan cooking videos I should do, please!! I haven't done any cooking 
videos in a while and I miss it! So, let me know what you want me to cook! (Monami Frost, Instagram, 24,985 likes).

From this post, Monami garnered 185 comments, many with very detailed suggestions for future content. Although she does not always actively reply to every comment (doing so would be almost impossible), viewers clearly appreciate the chance to contribute to the creation of Momani's community, and find value in discovering new meals to cook and new places to visit. Through my auto-netnographic observations, I garner a glimpse of different modes of selfhood and consumption practices, which in turn, feed my own consumption fantasies (Donnar, 2017). By watching Monami and other food influencers, I come closer to realising my own desires. She embodies, embraces and enacts a lifestyle that I am keen to personify. The 'what I eat in a day' or 'what I eat in a week' videos always garner many views. Monami has at least 50 'what I eat in a day' videos and 50 'cook with me' videos which all focus on food content. Feedback derived as a consequence of these videos helped to solidify her project as her audience reflected back their likes and dislikes:

\footnotetext{
"Only a couple of days ago I posted the cookie recipe video and already so many of you have tried them! Make's me incredibly happy to see you guy's trying the recipes I post. Video on my YouTube channel" (Monami Frost, Instagram, 11,511 likes, 134,768 views).

"I tried these cookies and I thought they were brilliant! I shared them with my friends, and they loved them" (Poster on Instagram).

"OMG thank you so much! I REALLY loved the cookies. Everybody I gave them to loved them also. Keep up the good vegan recipes :-)" (Poster on Instagram).
}

These cookies ended up on Frost Burgers menu, along with the burgers, sauces, and doughnuts, all of which she developed in conjunction with follower feedback. Her experimentation with content and the ability of social media feedback to direct, in interactive loops, her production of ever more attractive content, lead her to design innovative fast food.

\section{Ideating product concepts attuned to the needs of a specific target market}

If the success of content creators is largely dependent on their ability to conjure up and realise their best ideas, then it is imperative that they maximise the opportunities to do so. Monami Frost does so in a number of ways. She documents her global travels in search of inspiration and steeps herself in the culture of the best vegan fast food, such that she understands it implicitly and intuitively. Cue the ongoing worldwide whirlwind tour that sees her variously sampling and critiquing an Impossible Burger in Los Angeles, having fries in Kraków, Poland, House Garlic Dill Pickles in Calgary, Canada and so on. Many of the ideas she incorporates into the restaurant draw upon her idiosyncratic life experiences and as such lend her an air of authenticity. Monami, for instance, describes the process of creating the artwork that decorates the restaurant:

\footnotetext{
"This is Sub Zero, from Mortal Kombat - and as a kid I thought Sub-Zero was super cool because he is all about ice. He's shooting ice. I don't know how to explain it really but he's the Ice Man I am too Mrs Frost and all about snowflakes. So for a very long time my husband used to make references that I look like Sub-Zero because I used to wear like face masks, like you know the snowboarding face masks and bandanas and stuff like that, and because I am Frost he would always call me Sub-Zero.
}

Monami Frost, YouTube, 28,469 views

By cleverly combining her name and videogame obsession she designed a uniquely personal servicescape. 
Another method of creating new ideas, becoming more commonplace in the food industry, is to involve customers in ideation. At Frost Burgers, consumer participants were, and are, actively engaged in co-creating many aspects of the experience on offer. During her 8-year stint on YouTube and Instagram Monami consciously develops her community and brand through the reflective process of content production, re-production, digesting feedback and interacting with followers. Frost has successfully established her business as part of the Liverpool restaurant scene. Monami's use of design thinking has allowed her to access this marketplace through empathetically understanding "the highly distributed and parallel actions of consumers on objects and the reciprocal actions of these objects on the same and other consumers" (Martin and Schouten, 2014, p. 855). Monami stays in tune with what her audience craves via the feedback she garners on social media. For example, during the process of interacting with her followers about her vegan recipes, Monami received the following feedback:

“@Monamifrost if you ever come out with another book it should be called 'FROST BITES' like other stuff you eat or snacks. We need this!” Poster on Instagram

Monami clearly listened and acted upon this feedback as 'Frost Bites' are now a mainstay of the Frost Burgers menu (see Image 1). Fundamentally, Monami understood that her customers sought a novel vegan venue. The closeness she maintains to her audience allows her to ideate an offering that is finely attuned to its needs, a specific target market of radical foodie vegans.

$\underline{\text { Insert Image 1: Frost Bites }}$

\section{Prototyping product concepts as a result of engaged and targeted social media immersion} Monami's burgers are a great example of prototyping at work. Although its ubiquitous meatfilled cousin has earned itself a bad reputation for providing poor nutritional quality, the burgers on sale in Frost Burgers are quite healthy, largely due to the high quality of the ingredients. Like all burgers, they consist of an artfully arranged collection of different ingredients - the sauces, the vegan cheeses, the meat-free patties, the vegetables, and the bread buns. All these items have been carefully sourced and tested by Monami. One can view videos of her testing some of these individual ingredients such as the one where she tests an array of different dairy-free cheese, or sips a variety of flavoured alternative proteinbased milkshakes.

Monami also has an army of devoted followers who are more than willing to taste test her produce. I followed Monami's social media accounts very closely in the run up to her restaurant opening, checking regularly for fresh posts. Occasionally, I mentioned updates to my husband about when the restaurant would open. Although I may normally regard myself as being a sceptical consumer, I was eager to sample the vegan delights that Monami designed. During the 4-month period between this initial announcement and the actual opening of the restaurant, Monami posted regular updates about the prototyping of the food that would be sold in the restaurant. She also told stories about how she overcame hurdles that momentarily hindered the preparation of the venue. For example, she detailed how she had to purchase second-hand appliances because new ones were out of her budget. She convinced people about her authenticity and devotion with stories such as how she easily persuaded passionate vegan followers to work in her restaurant, given that they were already converts to her cause. These raw honest tales were also counterpointed against a slick professionally made promo video that presented the restaurant in pristine condition. All of 
which served to whet appetites and heighten my own personal craving to taste her food offerings.

As noted throughout these findings, Monami often crowdsources feedback and interacts publicly with her consumers about the design and re-design of her products. One recent example is where she discusses with her followers what they think of using the 'beyond' burger in her restaurant. She received 138 comments and replied to many:

\footnotetext{
"How long do you think you'll be using them?" Instagram Poster

"We aren't sure at the moment! But like we said if we get good feedback, we may keep them indefinitely!" Monami Frost Reply

"I didn't realise that you didn't make those burgers yourselves, on the premises. Can you tell us who you get them from then? I won't be making the trip to Liverpool anymore for beyond burgers I'm afraid. Do let us know when you are back to business as usual.' Instagram Poster

"We're sorry to hear this, as soon as our usual manufacturers can supply again, we will let you know!" Monami Frost Reply

"Great service, great food and it's understandable to not be able to get hold of products from time to time, but I would definitely keep the beyond burgers for GF people only if you're able to get your original ones back.” Instagram poster
}

Testing retail experience and products on an already willing, educated, and devoted market When I learned the restaurant's opening date, I knew I had to be there. It was an event I had looked forward to for a long time, and a chance to turn my deep personal engagement with Monami's social media content into an intimate personal experience. The store's design met with my immediate approval and admiration. The restaurant has a delightfully transgressive and dark aesthetic. Hip-hop classics pulsate through speakers. The black walls are splattered with colourful graffiti. A large graphic by a famous artist depicts a character winning a battle against the Frost Burger mascot, Sub-Zero. I knew about the restaurant and could decode its meanings because I was a member of the Frost tribe, educated through social media on the significance of things such as the image of Sub-Zero and its links to Monami's videogaming passion. This is culture made manifest through experience design, enacted through a social media community. Just like Monami's tattoos, everything in the retail location is carefully considered. From the story on the walls to the adorable stickers that come free with the meal to the carefully curated burger (see Image 2).

There is even a can crusher where you can demonstrate how much you care for the environment by taking a little affirmative muscular action of your own. The staff are tattooed and bejeweled much like Monami. The customers, aside from us, are for the most part, much like Monami too. Their turns of phrase, manner of speech and gestures all remind me of her. A little online subculture of instabuddies who share food and fashion perspectives has materialised to populate this glorious tableau vivant.

\section{Insert Image 2: The First Image of a Frost Burger Shared on Instagram}

For that first encounter with food made by the influencer I had admired and followed for years, I brought my appetite. I had a 'fish-free' burger, like a fillet au fish at McDonald's and a 'beef free' burger, like a Burger King Whopper. It was just as I had imagined it would be. From this day forth, I believe that living as a vegan foodie in Liverpool would be significantly easier. I had found my home away from home. It resonated, and deeply so, not least because I had watched it emerge on social media over several years. Along with the rest of Monami's audience, I had watched this restaurant and the food in it develop from nothing but an idea she had shared with and built with all of us. I had intimate knowledge of its 
immaculate conception. As she states:

I wanted to create a place where I would want to hang out and that would be amazing you know. You know it's all about detail I really was focusing on detail because I think just everything means so much to me about this place means everything you know and I just thought so much about every single detail and I think details make the place what it is you know and putting your heart into all of that just makes it all worth it and I think people appreciate it and see it so yeah.

Monami Frost Speaking in her YouTube Video 'The making of Frost Burgers Artwork', Jan 20 ${ }^{\text {th }} 2019$, 28,469 views

Opening the restaurant has not been completely smooth sailing. There have been teething problems, most of which have played out on social media. One problem has been the materials used for packaging the food. The milkshake cups are plastic, which angered some people. Others became a little disgruntled when they mistakenly assumed that the saucepots and drinking straws were made from non-degradable, environmentally harmful plastic. Whenever problems like this arise, Monami is quick to address them either on her YouTube channel or the Frost Burgers Instagram. She always does so in a very honest and direct fashion. In the following quote she convincingly addresses the issues surrounding her apparent use of plastic packaging:

"Lots of people have shown concerns every time we post a picture of our milkshakes or where you can see our little sauce pots and they look plastic. That is compostable plastic that is made from plants, so it is biodegradable and it doesn't stay on this planet forever like plastic does which is amazing, and as already mentioned our cups for milkshakes are plastic for now, that is one thing that we want to change asap. As we started this whole thing we had no idea how much it would cost and we kept getting bills for construction and things that we needed to do that we didn't count on and we were drained out....I was trying to sell my clothes and everything that I could, just to be able to open this place, so we weren't able to afford making the cups compostable. We couldn't afford to make them because we would need to order twenty thousand cups, and that costs a lot of money and we weren't able to afford them at the start but as soon as we can that is the first thing on our list because that is what we strive for.

Monami Frost, YouTube Video, 47,704 views

Although the textual transcription of this post inevitably loses something of the impassioned camera-facing performance that Monami deftly fronts (indeed her verbal acuity is one of the reasons I keep returning to view her content), I hope it is still evident that her message is designed to emotionally reverberate with, and affect, her followers. For instance, her discourse borrows from the classic trope of romanticizing poverty. She practically claims that she would happily 'sell the shirt off her back' so long as it advances her primary agenda to contribute to the wellbeing of the planet.

Following in the popular trend of purpose-based marketing, her discourse asserts that principles, rather than mere profits, are what motivates her. She knows her markets, as this is a very appealing position to customers like me. As well, she is consistent. Monami has been unfailingly responsive to the feedback of her consumers. True to her word, six months after the original commotion over the plastic packaging, Monami delivered on her promise to make it fully compostable. In posts on both Facebook and Instagram, Frost Burgers wrote to their consumer base to tell them the good news:

"Compostable cups are here! Made from plants! We are so excited that finally all of our packaging is recyclable/compostable! We are so happy we can share this news with you. We try our best however 
we can! Also, our rubbish collection company had a 100\% recycling promise! And we love that!" Monami on Instagram, 2,192 likes and 28 comments.

For the most part, after the announcement of this news, Monami was greeted with overwhelmingly positive affirmation by those who follow her:

"Thank you so much for doing your part to help the planet - I wish more businesses were like you!" Instagram Commenter

In my field journal, I have also repeatedly noted the seriousness with which she takes the feedback garnered from the followers who taste, test and try her produce. Pleasing them is tremendously important to her. For instance, after followers passionately requested Monami to add a takeaway option to the restaurant, she quickly got to work on making that happen. Speaking to her followers via Instagram, Frost Burgers joyfully reported, "Exciting news. From tomorrow we are gonna be available on Deliveroo. You asked, and we listened." Serving the marketplace with multiple fulfilment options is necessary for contemporary food outlets, but the Frost Burgers fans seemed especially elated by this news, feeding back 245 highly emotive, joyful and ecstatic comments like: "That is phenomenal, she must have heard us", and "Might as well just accept it, I'm gonna get chubby" (Comments from Frost Burgers Instagram).

\section{Discussion: Design Thinking and Analysis}

In this paper we have witnessed how a popular content creator uses a variety of specific practices in order to develop empathy, define, ideate, prototype and test new ideas with her audience and, by extension, with the market or markets in which she operates. Each time content creators post content onto social media, they operate as informational entrepreneurs in an attention economy, just as Smith and Fischer (2020) explains. Through those practices, they gain swathes of nuanced and detailed feedback. As their popularity rises, engagement may decrease, but useful comments (as a net percentage of overall activity) may continue to increase, providing them with more opportunities for feedback, more opportunities for pattern development, and more chances to create and tailor successful marketplace offerings. As a consequence, they modulate their self-presentation, such that future content they produce is more in sync with what they believe their viewers collectively desire. Through there active presence on social media, they consistently engage with the issues and concerns raised by their followers. By working with and learning from their followers they can conjure up exciting new experiences and transform an audience into a market.

From a method perspective, the empathy and relationship between a long-term audience member and the entrepreneur/designer/marketer are laid bare. Intimate and up-close in its data collection and cultural analysis, the auto-netnography component of this research reveals the response of one highly attuned audience member to these design inspired movements. The method reveals in high relief, in a way that few others could, how this feedback loop built on a genuine social media relationship deepens over time. It shows how the relational intimacy of feedback and response is received and the loyalty and resonance they inspire. It suggests that the followers of content creators, such as the lead author of this paper, might naturally adopt the food practices and eating habits of content creators and are also, in a sense, imitating them. The auto-netnography suggests, therefore, a type of feedback loop: a two-way process of adaptation and imitation that over time binds follower and influencer in a truly close embrace. 
Followers of healthy food content creators may feel that they are doing something that is good for them simply by watching this content online, as the auto-netnography in this paper suggests. The exultant positivity of copious comments demonstrates that followers of Monami Frost also view the following of her life and food experience on social media as an extremely pleasurable act, a type of social media interaction. Her food is commensurate with Batat et al's (2019) depiction of food as art experience where consumers appreciate the production process, are personally involved, expressive, communal, creative, and develop narratives that they savour. Experiencing such food experiences could help consumers to "develop and adopt sustainable healthy eating behaviours and help them to achieve their overall food well-being" (Batat et al, 2019, p. 394). Costa et al. (2019), who interviewed vegan women about their eating habits, found that their chosen lifestyle engenders them with "a stronger sense of control and agency, more meaningful social relationships, and a sense of connection to a vegan sub-culture" (Costa et al. 2019, p.142). Certainly, similar insights are in evidence within the first author's auto-netnography. She writes passionately about how following Monami and others like her made her feel part of a like-minded community. The activity also helped her dispel her anxieties about how food might affect her body and gave her the confidence to be more adventurous in her own cooking and diet choices. Bourdieu might have called such issues "petit-bourgeois suffering", but to many women and men, their relationship with food is the source of much apprehension. Being connected to a social network of like-minded others and sharing experiences encourages the emergence of a sense of community. The belonging from this sense of community contributes to and impacts wellbeing at the individual, social and ecological level (Larson et al, 2015).

Given such a contextualized viewpoint, we might assert that Monami Frost's focus on living a positive, healthful life as depicted in her YouTube videos signals a number of enabling ways for her followers to tap into a wellspring of wellness. Firstly, and perhaps most importantly, her brand offering neatly aligns with millennial values. That she uses quality ingredients, wrapped up in recyclable or compostable packaging is important, but it is her philosophy of values-driven marketing that really strikes a chord. As LoRusso (2017, p. 13) notes, advocates of said philosophy, "promote the idea that ethically attuned business owners are best equipped to address the depraved temporal and spiritual state of the world."

Secondly, the interactional nature of her social media accounts promotes the emergence of a community collective of socially minded activists who reside within an open, supportive and safe online space. As members of the same tribe, they find sustenance not just in the food, but equally from the social relations and "linking value" that food following, vlogging, commenting, and restaurant attending facilitate (Cova et al. 2007). Thirdly, Frost Burgers, as a physical manifestation of this community, strengthens the collective bond developed online by providing a social touch point (Larson et al. 2015) where people's online desire for a 'piece of Monami' are realized in a way that is communally pleasurable and celebrated. Fourthly, collecting evidence of the physical experience of eating at Frost Burgers and posting it back online in the form of pictures, reviews, videos and stories offers a way of reflecting and extending her follower's pleasure.

\section{Combining Design Thinking and Netnography}

In this paper, we have used auto-netnography as a method of revealing how the relatively novel and rapidly evolving field of content creation is using the principles of design thinking to undertake consumer driven market emergence strategies and food innovation. As we noted earlier, although design thinking has drawn from multiple disciplines, it has not yet been 
explicitly connected with the many benefit of netnographic research. In this paper we show how netnography is particularly adept at researching people and their contexts by accessing data that is "Raw. Authentic. Spontaneous. Indigenous. Unforced. Unadorned. Powerful. Highly involved and often spectacularly creative" (Kozinets, 2010a, p. 1). As it has for dozens of companies and thousands of researchers, netnography offers design thinkers and design researchers a proven, practical and useful way to deeply explore the networked patterns of behaviour and relationships on social media, such as exist between the posters and followers in this paper. For those individuals interested in developing consumer centric and highly empathetic solutions such as that presented in this paper, easily accessing data via netnographic research, in any of its four main types (auto, digital, symbolic or humanist), with these characteristics is extremely valuable.

Yet, because of the emphasis on empathy, we believe that auto-netnography may be the most suitable means for design-driven investigations. Auto-netnography, especially, offers a deep level of personal engagement, an immersed encounter of the continuous feedback loops or 'networks of desire' that provide the lifeblood of today's "technocultural consumption" landscape (Kozinets et al, 2017; Kozinets 2020). In a world where designers are tasked not merely with understanding the needs of disparate, disconnected, isolated individual consumers, but must understand the continuously connected, always-on, networked and content-driven society of today, netnography seems an incredible boon. Netnography also reveals current trends and concerns. In this case, it allowed the researchers to view a successful, innovative, and market-based development of an influencer initiated and valuesdriven marketing prospect. With Monami Frost, a content creator innovatively leveraged her social media presence, knowledge, and extant infrastructure to create a new marketplace offering. That offering was able to address audience concerns about food quality and health, ecological impacts, and the psychological and physical wellbeing of consumers.

Her deep knowledge of her own radical vegan audience, and her gathering of this "tribe" (Cova, 1997) enabled the design principles of empathizing, defining, ideating, prototyping, and testing to take place in novel contexts and with levels of ongoing depth that have not yet appeared in the design literature.

Our methodological advocacy is not meant to downplay that the challenges accompanying the use of a method such as auto-netnography. Netnography requires enormous personal investment, commitment, time, energy, focus, attention. Because of the depth of understanding, insight, and empathy required, auto-netnography is probably best suited for those who are already deeply enmeshed in particular realities. If you are a committed cat lover, a devoted surfer, or a vinyl afficionado - turn your online passions into research and pursue your auto-netnography. In this case, the first author of this paper could not have completed this project without an already existing and enormous commitment to and familiarity with not only food and vegan food culture, but also to content creators, and social media content.

Nonetheless, the rewards are significant. Online ethnography such as netnography encourages designer and marketers to start to focus on particular communities, to become "embedded" designers, researchers, and marketers - to reach out and join communities. This process, although requiring significant amounts of commitment, time and focus, is extremely fulfilling and effective when done well. YouTube is a particularly large and detailed online universe housing a vast multitude of different consumer segments and revealing an incredible diversity of marketplace activities and consumption experiences. Food is but one context that receives a large amount of attention online. Besides food, the areas of fashion, health, sports, pets, 
entertainment, technology, beauty, fitness, and many others (including those involving business-to-business) contain abundant and detailed consumption data from content creators. We have attempted to show in this paper that empathy, which is a key stage in design thinking, is facilitated by processes of understanding that are undertaken both by content creators when they review and adapt to the comments of their audiences as well as by autonetnographers when they study phenomena such as these. Both of these activities benefit from the structured, disciplined reflective acts of watching, listening, and re-considering your own self and actions in relation to a particular goal, whether it is market or audience development, or scientific development of ideas about marketplaces and influencer marketing.

\section{Limitations}

As with most inductive research, generalisability is not the main aim of this study, nor its central claim. Rather, we seek to create in-depth explanations and meanings of our context and contributions to theoretical discourses, such is appropriate in interpretive work (Strauss and Corbin, 1998). Our account is a rich exploration of a case of entrepreneurial design that uses social media influencers and their followers. We believe that there may be similar cases in other social media spheres. Oftentimes, famous influencers such as Kylie Jenner or Jeffree Star create products and brands specially tailored to the tastes of their social media audience. However, it will take further research to develop and verify the manner in which these principles work in other cases. The longitudinal immersion and depth of our engagement within the area of food content creators equipped us with an innate familiarity with the design processes at work. We hope that others will feel inspired to develop work in other sites that help to develop an understanding of the design processes and principles we describe.

\section{Conclusion}

Through a multiperspectival process of continually tapping into the wellbeing needs and life values of their followers, online content creators such as Monani Frost are able to design and launch innovative and profitable food ventures. Such a strategy is closely affiliated with the idea that contemporary consumers, millennials in particular, "don't want to be handed cookie-cutter products, services, and experiences; they want to help co-create the products, services, and experiences" (Rossman and Duerden 2019, p.157). In this paper, we offer a detailed 5-stage process through which an online content creator develops and adapts her new food offering using variants of design thinking skills and strategies. Designers, marketers, and other content creators might closely study, listen to and interact with consumers by employing a similarly staged process. The process was revealed through auto-netnography, which we suggest offers exciting possibilities for the enactment and development of design thinking in the marketing field.

How incidents such as the 'storm in a plastic-cup' crisis, for instance, are addressed and ameliorated can reveal further important procedures and responses relating to the crisis communication and reputation management functions traditionally associated with public relations, but now assumed by individual content creators such as Monami Frost. By the same token, as we have demonstrated throughout this paper, the minutiae of many other processes 
and interactions, parts of a new technocultural world and dimension in which the socialities of embodied being and digital audiencing easily and repeatedly overlap, are revealed to researchers, designers, and marketing managers.

Following auto-netnographic procedures, which are difficult, empathic, and important, our close scrutiny and deep understanding of this site of content, connection, and meaning gradually revealed themes of health, discourses of ecology, and practices of intimacy and authenticity that emerged, advanced, and repeated over time as the content creator moved from marketing her own persona and online content to opening a new restaurant and developing her menu and actual food services (including such things as packaging and hiring practices). We look forward to a stream of work that uses similar methodological procedures to add to our understanding and theorizing of the role of design thinking and marketing in the rituals, expectations, roles and routines of other influencers and designers.

\section{References}

Alvesson, M., and Sköldberg, K. (2009). Reflexive Methodology. London: Sage Publications. Archer, L.B. (1995), The Nature of Research, Co-design, January

Ashman, R., Patterson, A. and Brown, S. (2018), “Don't Forget to Like, Share and Subscribe': Digital Autopreneurs in a Neoliberal World”, Journal of Business Research, Vol. 92, pp. 474-483.

Batat, W., Peter, P, C., Moscato, E, M., Castro, I, A., Chan, S., Chugani, S. and Muldrow, A. (2019), "The Experiential Pleasure of Food: A Savoring Journey to Food WellBeing”, Journal of Business Research, Vol. 100, pp. 392-399.

Best, K. (2006), Design Management: Managing Design Strategy, Process and Implementation, Thames \& Hudson, London, England.

Bilgram, V., Bartl, M., and Biel, S. (2011), "Getting closer to the consumer-how Nivea cocreates new products", Marketing Review, Vol. 28, No. 1, pp. 34-40.

Brenner, W. and Uebernickel, F. (2016), Design Thinking for Innovation, Research and Practice, Springer International Publishing, Switzerland.

Buchanan, R. (1992), "Wicked Problems in Design Thinking”, The MIT Press, Vol. 8, No. 2, pp. 5-21.

Carlgren, L., Rauth, I., \& Elmquist, M. (2016), "Framing design thinking: The concept in idea and enactment", Creativity and Innovation Management, Vol. 25, No. 1, pp. 38-57.

Christensen, B., Ball, L. and Halskov, K. (2017), Analysing Design Thinking: Studies of Cross-Cultural Co-Creation, CRC Press/Taylor \& Francis, Leiden. 
Coates, A, E., Hardman, C, A., Grovenor J, C., Halford, P, C., and Boyland, E, J., (2019), "Food and beverage cues featured in youtube videos of social media influencers popular with children: an exploratory study", Frontiers in Psychology, Vol.10, pp. 2142.

Costa, I., Gill, P, R., Morda, R. and Ali, L. (2019), “'More than a Diet': A Qualitative Investigation of Young Vegan Women's Relationship to Food", Appetite, Vol. 143, pp.1-8.

Cova, B. (1997), "Community and consumption: Towards a definition of the "linking value" of product or services", European Journal of Marketing, Vol. 31 No. 3/4, pp. 297-316. Cova, B., Kozinets, R, V. and Shankar, A. (2007), Consumer Tribes, Routledge, New York, NY.

Donnar, G. (2017), "Food Porn or Intimate Sociality: Committed Celebrity and Cultural Performances of Overeating in Meokbang", Celebrity Studies, Vol. 8 No. 1, pp. 122-127.

Dell'Era, C., Magistretti, S., Cautela, C., Verganti, R., \& Zurlo, F. (2020), "Four kinds of design thinking: From ideating to making, engaging, and criticizing", Creativity and Innovation Management, Vol 29, No. 2, pp. 324-344.

Friedman, K. and Stolterman, E. (2015), "Series Foreword" in Dorst, K. (ed.) Frame Innovation: Create New Thinking By Design, London, MIT Press.

Gregory, S. (2018), "Design Anthropology as Social Design Process", Journal of Business Anthropology, Vol. 7 No. 2, pp. 210-234.

Hayano, D. (1979), “Auto-Ethnography: Paradigms, Problems, and Prospects”, Human Organization, Vol. 38 No. 1, pp. 99-104.

Hillgren, P-A., Seravalli, A. and Emilson, A. (2011), "Prototyping and Infrastructuring in Design for Social Innovation”. CoDesign, Vol. 7, No. 3-4, pp. 169-183.

Howard, L. (2020), “Auto-Netnography in the Education Field”, in Kozinets, R.V., Gambetti, R. (Eds.), Netnography Unlimited, Sage Publications, London, UK, Forthcoming.

Iskander, N. (2018), "Design Thinking is Fundamentally Conservative and Preserves the Status Quo", available at: https://hbr.org/2018/09/design-thinking-is-fundamentallyconservative-and-preserves-the-status-quo (accessed 25th February 2020).

Jonson, B. (2005), "Design Ideation: The Conceptual Sketch in the Digital Age", Design Studies, Vol. 26, No. 6, pp. 613-624.

Kolko, J. (2014), Well Designed: How to use Empathy to Create Products People Love, Harvard Business Review Press, Boston, MA.

Köppen, I., and Meinel, E. (2015), "Empathy via Design Thinking: Creation of Sense and Knowledge in: Plattner, H. Meinel, C, and Leifer, L. (eds), Design Thinking Research: Building Innovators, Springer, New York, pp. 15-28.

Kozinets, R, V. (2010a), "Netnography: The Marketer's Secret Weapon,” NetBase White Paper, Mountain View, CA: NetBase Inc. 
Kozinets, R, V. (2015), Netnography: Redefined, $2^{\text {nd }}$ Edition, Sage Publications, London. Kozinets, R, V. (2020), Netnography: The Essential Guide to Qualitative Social Media Research, $3^{\text {rd }}$ Edition, Sage Publications, London.

Kozinets, R, V., De Valek, K., Wojnicki, A, C. and Wilner, S, J, S. (2010), "Networked Narratives: Understanding Word-of-Mouth Marketing in Online Communities", Journal of Marketing, Vol. 74 March, pp. 71-89.

Kozinets, R,V., Kedzior, R. (2009), "I, Avatar: Auto-Netnographic Research in Virtual Worlds," in Solomon, M., Wood, N. (Eds.), Virtual Social Identity and Social Behavior, Armonk, New York, NY. pp. 3-19.

Kozinets, R., Patterson, A. and Ashman, R. (2017), "Networks of Desire: How Technology Increases Our Passion to Consume", Journal of Consumer Research, Vol. 43 No. 5, pp. 659682.

Krupinska, J. (2014), What an Architecture Student Should Know, Routledge, New York.

Kurokawa, T. (2015), Service Design and Delivery: How Design Thinking Can Innovate Business and add Value to Society, Business Expert Press, New York.

Larson, E, C., Luloff, A, E., Bridger, J, C. and Brennan, M, A. (2015), “Community as a Mechanism for Transcending Wellbeing at the Individual, Social, and Ecological Levels", Community Development, Vol. 46 No. 4, pp. 407-419.,

Liedtka, J. (2014). "Innovative ways companies are using design thinking", Strategy and Leadership, Vol. 42, no. 2, pp. 40-45.

Liedtka, J. (2015). "Perspective: Linking design thinking with innovation outcomes through cognitive bias reduction." Journal of Product Innovation Management, Vol 32, No. 6, pp. 925-938.

Lockwood, T. (2009). "Frameworks of Design Thinking", Design Management Journal, Vol. 4, No. 1, pp. 3-9.

Macdonald, A. (2003), "Humanising Technology", in Clarkson, M., Coleman, R., Keates, S, and Lebbon, C. (eds), Inclusive Design: Design for the Whole Population, Springer, London, England.

Mardon, R., Molesworth, M. and Grigore, G. (2018), "YouTube Beauty Gurus and the Emotional Labour of Trible Entrepreneurship", Journal of Business Research, Vol. 92, pp. 443-454.

Martin, D, M. and Schouten, J, W. (2014), "Consumption Driven Market Emergence”, Journal of Consumer Research, Vol. 40, No. 5, pp. 855-870.

Mariampolski, H. (2006), Ethnography for marketers: A guide to consumer immersion. Sage, London. 
Micheli, P., Wilner, S. J., Bhatti, S. H., Mura, M., \& Beverland, M. B. (2019), "Doing design thinking: Conceptual review, synthesis, and research agenda", Journal of Product Innovation Management, Vol. 36, No. 2, pp 124-148.

Neumeier, M. (2009), The Designful Company; How to Build a Culture of Nonstop Innovation, New Riders, Berkeley, CA.

O’Reilly, N, J., Rahinel, R., Foster, M, K., and Patterson, M. (2007). "Connecting in megaclasses: The netnographic advantage", Journal of Marketing Education, Vol. 29, No. 1, pp. 69-84.

Patterson, A., and Ashman, R. (2021), "Getting Up Close and Personal with Influencers: Reflecting on the Intimacy of Netnography", in Kozinets, R., and Gambetti, R. (Eds.), Netnography Unlimited: Understanding Technoculture using Qualitative Social Media Research, Routledge, New York.

Pressman, A. (2018), Design Thinking; A Guide to Creative Problem Solving for Everyone, Routledge, London.

Polaine, A., Løvlie, L. and Reason, B. (2013), Service Design: From Insight to Implementation, Rosenfeld, New York.

Rathbone, R, A. (1950), Introduction to Functional Design, McGraw-Hill, New York.

Raun, T. (2018), "Capitalizing Intimacy: New Subcultural Forms of Microcelebrity Strategies and Affective Labour on YouTube", Convergence: The International Journal of Research into New Media Technologies, Vol. 24 No. 1, pp. 99-113.

Reyero, V. (2019), The Value of Anthropology in Design Thinking, Antropologia 2.0, Available at: https://blog.antropologia2-0.com/en/the-value-of-anthropology-in-designthinking-2/ [Accessed on $12^{\text {th }}$ February 2020].

Rittel, H, W., Webber, M. M. (1973), "Dilemmas in a General Theory of Planning”, Policy Sciences, Vol. 2, No. 2, pp. 155-169.

Rodgers, P, A., Yee, J. (2015), The Routledge Companion to Design Research, Routledge, Oxon, UK.

Rossman, R., Duerden, M. D. (2019), Designing Experiences, Columbia University Press, New York, NY.

Rowe, P, G. (1987), Design Thinking, The M.I.T Press, Cambridge, Massachusetts.

Rundle, T. (2013), Visual Contrast: The Art of Display and Arrangement, Ryland Peters \& Small, Mountain View, CA.

Saariluoma, P., Cañas, J.J., Leikas, J. and Saariluoma, P. (2016), Designing for Life; A Human Perspective on Technology Development, Palgrave Macmillan, London, UK. 
Simon, H, A. (1968), The Sciences of the Artificial, The MIT Press, Cambridge, Massachusetts.

Smith, P, G., Reinertsen, D, G. (1991), Developing Products in Half the Time: New Rules, New Tools, Van Nostrand Reinhold, New York, NY.

Smith, A. and Fischer, E. (2020) "Pay attention, please! Person brand building in organized online attention economies", Journal of the Academy of Marketing Science. Forthcoming, https://doi.org/10.1007/s11747-020-00736-0.

Stappers, P, J., Visser, F, S. and Kelle, I. (2015), "The Role of Prototypes and Frameworks for Structuring Explorations by Research through Design", in Rodgers, P., and Yee, J. (eds.), The Routledge Companion to Design Research, Routledge, Oxon, UK, pp. 163-174.

Strauss, A., Corbin, J, M. (1998), Basics of Qualitative Research: Techniques and Procedures for Developing Grounded Theory, Sage Publications, New York, NY.

Syrjälä, H., Norrgrann, A. (2018), “Autoethnography in The Digitalized World: Using AutoNetnography in Analyzing Object Agency in Home Assemblage", in Syrjälä, H., and Norrgrann, A. (Eds.), Multifaceted Autoethnography: Theoretical Advancements, Practical Considerations and Field Illustrations, Nova Science Publishers, New York, NY, pp. 147180.

Villegas, D. (2018), "From the Self to the Screen: A Journey Guide for Auto-Netnography in Online Communities", Journal of Marketing Management, Vol. 34 No 3-4, pp. 243-262.

Wang, Y-S. (2018), "Addiction by design: Using netnography for user experiences in female online gambling game", International Journal of Human-Computer Interaction, Vol. 34, No. 8, pp. 774-785.

Wilkinson, C. and Patterson, A. (2014), "Peppa Piggy in the Middle of Marketers and Mashup Makers: A Netnography of Absurd Animation on YouTube", in Brown, S. and Ponsonby-McCabe, S. (Eds.), Brand Mascots: And Other Marketing Animals, Routledge, London, UK, pp. 123-140. 